\title{
SOCIEDADE ESTAMENTAL: O CRIME E OS DONOS DO PODER
}

\author{
ESTATE SOCIETY: CRIME AND POWER OWNERS
}

\author{
Patricia Manente Melhem ${ }^{1}$ \\ Rudy Heitor Rosas ${ }^{2}$
}

\begin{abstract}
RESUMO
Mediante revisão bibliográfica e análise qualitativa, aborda-se a categoria "sociedade de estamento", conforme Faoro, relacionando-a à Ideologia da Defesa Social, tratada no contexto marxista apresentado por Baratta como discurso dominante sobre o crime no capitalismo e tem entre seus postulados a afirmação de que as condutas consideradas criminosas o são porque é de interesse social que o sejam, sendo a lei a expressão da vontade geral. Procura-se demonstrar que a lei na verdade não representa os interesses da sociedade e sim de grupos influentes no processo legislativo, que aqui passam a ser chamados de estamento.
\end{abstract}

Palavras-chave: Estamento; Ideologia; Processo Legislativo.

\begin{abstract}
Through literature review and qualitative analysis the work deals with the category "stand society" in Faoro, relating to the Ideology of Social Defense, treated in the marxist context presented by Baratta as the dominant discourse on crime in capitalism and has among its postulates the claim that the conduct is considered criminal because of social interest, and the law is the expression of the general will. It seeks to demonstrate that the law does not actually represent the interests of society but of the influential groups in the legislative process, here called: "stands".
\end{abstract}

Keywords: Stand; Ideology; Legislative Procedure.

\footnotetext{
${ }^{1}$ Mestre em Direito pela Universidade Federal do Paraná. Doutoranda em Ciências Sociais Aplicadas pela Universidade Estadual de Ponta Grossa - Paraná (Brasil). E-mail: prof_patriciamelhem@ camporeal.edu.br

${ }^{2}$ Mestrando em Ciências Sociais Aplicadas pela Universidade Estadual de Ponta Grossa - Paraná (Brasil).
} 


\section{INTRODUÇÃO}

Toda a história do desenvolvimento da sociedade e do Estado demonstra o constante debate e dilema em torno das funções que cabem ao Estado cumprir e principalmente os limites a se respeitar no exercício de tais funções, notadamente o limite da esfera privada do cidadão. Neste aspecto, tema que se destaca é a atuação do Estado na garantia e manutenção da segurança pública, combate a atos desviantes e indesejáveis e aplicação de punições a seus cidadãos.

Mesmo os defensores de um estado mínimo, e principalmente estes, ao defender o enxugamento do Estado, ampliando a autonomia da iniciativa privada, jamais abdicam da necessidade de ser o Estado o grande guardião da sociedade, mantenedor da ordem, da segurança e do cumprimento dos contratos.

Justamente diante disto é que em geral, sejam vítimas ou ofensores, as pessoas costumam acreditar na necessidade de intervenção do Estado no combate ao crime, o que não é errôneo, porém, também em geral, acreditam que todos os meios devem ser empregados neste mister, muitas vezes não importando inclusive a flexibilização de garantias individuais.

Ocorre que entre o discurso da segurança pública e a realidade do funcionamento do sistema criminal há uma distância quase instransponível. Porém, a crença na necessidade da punição tal como ela é aplicada se mantém, ao arrepio dos fatos.

A Criminologia procura então explicar por que o senso comum insiste na defesa do sistema enquanto a realidade demonstra seus efeitos deletérios e principalmente sua desigualdade e seletividade.

É este o ponto de interesse do presente trabalho, que aborda o tema da Ideologia da Defesa Social, assunto em geral trabalhado dentro das Ciências Criminais, mais especificamente da Criminologia, mas que decorre diretamente da política, do modelo de Estado e de sociedade em um determinado momento histórico, que constroem as concepções sociais sobre criminalidade, violência, punição, entre outros.

Observa-se, a partir da Criminologia Crítica, a necessidade de se questionar até que ponto de fato a lei expressa a vontade geral da sociedade ou em que medida esta mesma sociedade é moldada de forma a acreditar em ideais que não são seus, mas que são oriundos de grupos de poder que tudo definem dentro do Estado, oriundos do chamado "estamento", na expressão de Raymundo Faoro.

O referido estamento arquiteta a sociedade conforme seus interesses e um dos principais 
instrumentos para a realização de tal arquitetura é o controle do processo legislativo, forjando-se leis que não expressam a vontade geral e sim a força dos grupos de poder em determinado momento histórico.

Esta contradição entre o senso comum sobre o crime e a realidade do sistema criminal é apontada por Alessandro Baratta, principal autor utilizado na primeira parte do presente trabalho, que se dispõe a explicar o que é a chamada Ideologia da Defesa Social, com crítica de base explicitamente marxista.

A sociedade patrimonialista e o estamento é abordada a partir do já mencionado Raymundo Faoro, bem como de Luiz Werneck Vianna.

Por fim, o tema das influências no processo legislativo e a artificialização dos delitos, é tratado a partir da chamada "Sociologia do Conflito", novamente com base marxista.

\section{QUEM SÃO OS DONOS DO PODER?}

De quem é?
De quem é?
De quem é o poder?
Quem manda na minha vida?
De quem é?
De quem é?
Uns dizem que ele é de Deus
Outros, do guarda da esquina
Uns dizem que é do presidente
Outros, quem vem lá de cima
(Cazuza)

(Cazuza)

Certamente um dos temas que ao longo dos séculos mais tem ocupado os cientistas políticos e sociólogos é o tema da legitimidade do poder do Estado.

Desde os pensadores mais clássicos até aos mais modernos, a questão acerca das razões da obediência humana ao um soberano (um indivíduo ou grupo), sacrificando sua liberdade individual, é questão intrigante.

A primeira das respostas encontradas foi a teológica, fundando-se a autoridade estatal na autoridade divina explicava-se a submissão, uma vez que aqueles que exercem o poder eram vistos como deuses ou verdadeiros representantes destes, motivo mais do que suficiente para que tivessem sua autoridade inquestionável.

O final da Idade Média e início da mentalidade moderna viu tais fundamentos serem duramente afrontados pelas teorias democráticas, que buscaram deslocar a origem do poder estatal de uma fonte divina para as mãos humanas. Surgem então as teorias da Soberania Popular e da 
Soberania Nacional. A primeira afirma ser o povo o titular do poder estatal:

A soberania popular, segundo o autor do Contrato Social e seus discípulos, é tão somente a soma das distintas frações de soberania, que pertencem como atributo a cada indivíduo, o qual, membro da comunidade estatal e detentor dessa parcela do poder soberano fragmentado, participa ativamente na escolha dos governantes. (BONAVIDES, 2004, p. 130).

Já a segunda, desloca o poder para ente abstrato denominado nação (conjunto de pessoas, tradições, cultura, símbolos e significados, das gerações passadas e inclusive das futuras), esta personificada nos representantes eleitos pelo povo, que em nome dela falam:

\begin{abstract}
A Nação surge nessa concepção com depositária única e exclusiva da autoridade soberana. Aquela imagem do indivíduo titular de uma fração de soberania, com milhões de soberanos em cada coletividade, cede lugar à concepção de uma pessoa privilegiadamente soberana: a Nação. Povo e Nação formam uma só entidade, compreendida organicamente como ser novo, distinto e abstratamente personificado, dotado de vontade própria, superior às vontades individuais que o compõem. (BONAVIDES, 2004, p. 132).
\end{abstract}

Tais concepções de poder fundam o Estado Moderno, racionalista, legalista, cientifista, imbuídas de todo o contexto do início da mentalidade moderna, impregnadas também do capitalismo $^{3}$.

Era importante encontrar limites ao poder do Estado e a lei se afigurava, racionalmente, como o melhor dos limites, notadamente por que, em Estados democráticos, ela seria fruto da vontade dos indivíduos por si ou representados em uma nação. Assim, ao obedecer, não se obedece simplesmente ao Estado e sim a sua própria razão. Incentiva-se o ex - súdito, agora cidadão, a crer que não mais obedece a Deus, ao Rei ou ao Estado e sim é fiel aos ditames de sua razão, soberano em sua autonomia privada.

Funda-se desta maneira o dito Estado Democrático de Direito.

É neste ponto que se encontram as interessantes reflexões de Raymundo Faoro na obra "Os donos do poder", em que verificará uma instância existente dentro da sociedade brasileira, que não é o povo, não é nação e não é o Estado, mas que é o verdadeiro detentor do poder, em virtude da maneira como se desenvolveu o capitalismo em nossa sociedade:

O capitalismo politicamente orientado — o capitalismo político, ou o pré-capitalismo —,

\footnotetext{
${ }^{3}$ A sociedade capitalista aparece aos olhos deslumbrados do homem moderno como a realização acabada da história — degradadas as sociedades pré- capitalistas a fases imperfeitas, num processo dialético e não mecânico, de qualquer sorte, substituindo o fato bruto ao fato racional, que bem pode ser o fato idealizado artificialmente. (FAORO, 2008, p. 869).
} 
centro da aventura, da conquista e da colonização moldou a realidade estatal, sobrevivendo, e incorporando na sobrevivência o capitalismo moderno, de índole industrial, racional na técnica e fundado na liberdade do indivíduo - liberdade de negociar, de contratar, de gerir a propriedade sob a garantia das instituições. A comunidade política conduz, comanda, supervisiona os negócios, como negócios privados seus, na origem, como negócios públicos depois, em linhas que se demarcam gradualmente. O súdito, a sociedade, se compreendem no âmbito de um aparelhamento a explorar, a manipular, a tosquiar nos casos extremos. Dessa realidade se projeta, em florescimento natural, a forma de poder, institucionalizada num tipo de domínio: o patrimonialismo, cuja legitimidade assenta no tradicionalismo - assim é porque sempre foi. (FAORO, 2008, p. 866, GRIFO NOSSO)

Trata-se de um modelo de sociedade que mantém a chamada "menoridade", do povo, cego pela necessidade da proteção estatal, permitindo que a tradição mantenha a confusão entre negócios particulares e negócios públicos. "Todos os Estados têm igual objeto: manter sua integridade; mas, sob esse escopo geral, há outros, de natureza particular" (FAORO, 2008, p. 866). Assim continua FAORO (p. 270):

\begin{abstract}
Característico principal, o de maior relevância econômica e cultural, será o do predomínio, junto ao foco superior de poder, do quadro administrativo, o estamento que, de aristocrático, se burocratiza (cap. III, 3) progressivamente, em mudança de acomodação e não estrutural. [...] Num estágio inicial, o domínio patrimonial, desta forma constituído pelo estamento, apropria as oportunidades econômicas de desfrute dos bens, das concessões, dos cargos, numa confusão entre o setor público e o privado, que, com o aperfeiçoamento da estrutura, se extrema em competências fixas, com divisão de poderes, separando-se o setor fiscal do setor pessoal. O caminho burocrático do estamento, em passos entremeados de compromissos e transações, não desfigura a realidade fundamental, impenetrável às mudanças. O patrimonialismo pessoal se converte em patrimonialismo estatal. Sobre a sociedade, acima das classes, o aparelhamento político - uma camada social, comunitária embora nem sempre articulada, amorfa muitas vezes - impera, rege e governa, em nome próprio, num círculo impermeável de comando.
\end{abstract}

O que há de bastante grave na constatação do autor, é que o mencionado estamento não tem caráter transitório, mas sempre esteve aí. Não se trata apenas da burocracia administrativa, em que alguns determinam as funções desempenhadas por seus hierarquicamente inferiores, mas sim de um estamento político.

O referido estamento está inclusive acima da luta de classe, superiora a elas:

O estamento burocrático comanda o ramo civil e militar da administração e, dessa base, com aparelhamento próprio, invade e dirige a esfera econômica, política e financeira. $\mathrm{O}$ estamento, por sobranceiro às classes, divorciado de uma sociedade cada vez mais por estas composta, desenvolve movimento pendular, que engana o observador, não raras vezes, supondo que ele se volta contra o fazendeiro, em favor da classe média, contra ou a favor do proletariado. Ilusões de óptica, sugeridas pela projeção de realidades e ideologias modernas num mundo antigo, historicamente consistente na fluidez de seus mecanismos. (p. 874)

Esta elite chamada estamento não é necessariamente a classe política, "a elite política do 
patrimonialismo é o estamento, estrato social com efetivo comando político, numa ordem de conteúdo aristocrático. " (p. 878)

$\mathrm{O}$ que mais se destaca no pensamento do autor e que mais interessa às finalidades do presente trabalho, é sua insistência no fato de que em uma sociedade assim regida por um estamento há uma grande confusão entre público e privado, há a utilização dos mecanismos públicos para finalidades particulares. "Ocorre que, no chamado novo Estado industrial, a atividade particular, nas organizações de larga envergadura, torna-se uma extensão da burocracia oficial, da qual depende e a cujas necessidades serve”. (p. 879)

Chega-se então ao ponto principal a que a presente análise se dedica, a influência do estamento nos resultados do processo legislativo, observando-se, com FAORO que, "a legalidade teórica apresenta, ressalvada a elegância da frase, conteúdo diferente dos costumes, da tradição e das necessidades dos destinatários da norma” (p. 881), ou seja, nada há de vontade geral na lei, ela trata sim da vontade do estamento.

Além da lei retratar apenas interesses particulares travestidos em interesses do povo ou da nação, cria-se em torno dela expectativas de potencialidade de mudanças sociais a partir de mudanças legislativas, intervenções nas ações e vontades humanas apenas mediante comandos normativos, que teriam o condão de mudar a realidade quase que magicamente:

Edifica-se nas nuvens, sem contar com a reação dos fatos, para que da lei ou do plano saia o homem tal como no laboratório de Fausto, o qual, apesar de seu artificialismo, atende à modernização e ao desenvolvimento do país. A vida social será antecipada pelas reformas legislativas, esteticamente sedutoras, assim como a atividade econômica será criada a partir do esquema, do papel para a realidade. (p. 882)

Reflete Rosivaldo Toscano Junior (2015), comentando a realidade brasileira, também a partir de Faoro:

Passados mais de cinquenta anos do texto de Faoro, vemos que não houve mudanças
consideráveis no cenário descrito por ele. O estamento continua aí. Mesmo após um revés
inicial, conseguiu, de certa forma, uma reversão parcial através da absorção dos
neopoderosos pelo estamento. Só pretensamente "a esperança venceu o medo", pois como
a estrutura estamental mal foi arranhada, aliada ao idealismo pueril de união entre capital e
trabalho, sem levar em consideração que em países periféricos o capital e seus donos ou são
de fora ou representam os valores e os interesses de fora. Assim, o chamado "pragmatismo
político" da pretensa renovação gerou concessões incompatíveis com à ética e desnaturou
ou desmobilizou os lutadores, convertidos ao estamento ou hipnotizados pela nova
condição.

No que se refere às questões legislativas direcionadas ao suposto combate ao crime, é bastante notável a realidade acima exposta, tanto a ilusão (deliberadamente incentivada entre os 
cidadãos) de que a lei conseguiria solucionar a violência na sociedade, como também a utilização da lei para a satisfação dos interesses de classes "ocultas" nos debates legislativos, tal como o aqui mencionado estamento.

\title{
3 ESTAMENTO, IDEOLOGIA E DISCURSO COMPETENTE
}

\author{
De quem é? \\ De quem é? \\ Quem inventou essa tara? \\ Uns dizem que ele é do povo \\ E saem pra trabalhar \\ Outros, que é dos muito loucos \\ Que não têm contas a prestar \\ (Cazuza)
}

Neste ponto do presente trabalho, pretende-se demonstrar como é possível relacionar as concepções sobre uma sociedade estamental, apresentadas por Faoro, com a ideia de Ideologia da Defesa Social, presente no senso comum sobre a atuação do Estado no âmbito criminal - aqui tratada a partir de Alessandro Baratta; e a ideia de Discurso Competente, tomada de Marilena Chauí, acerca do domínio sobre os saberes em nossa sociedade.

A hipótese central do presente texto é exatamente verificar como o estamento está por trás das definições ideológicas de crime, criminoso, desvio, pena, legitimidade do Estado para a punição, entre outros.

Parte-se primeiramente da noção de ideologia, segundo Michael Löwy (2015, p. 17),

\footnotetext{
É difícil encontrar na ciência social um conceito tão complexo, tão cheio de significados, quanto o conceito de ideologia. Nele se dá uma acumulação fantástica de contradições, de paradoxos, de arbitrariedades, de ambiguidades, de equívocos e de mal-entendidos, o que torna extremamente difícil encontrar o seu caminho nesse labirinto.
}

Ainda de acordo com LÖWY, o termo ideologia foi inventado por Destutt de Tracy, em 1801, que a entendia como "estudo científico das ideias", mas, como via a ideologia como um capítulo dentro da zoologia, afirmava que "as ideias são o resultado da interação entre o organismo vivo e a natureza, o meio ambiente". Posteriormente, em 1812, Tracy e seus discípulos teriam sido criticados por Napoleão, que os reputou meros “ideólogos, no sentido de especuladores metafísicos", e este foi o sentido que acabou preponderando na abordagem da palavra ideologia, inclusive na abordagem feita por Marx (apud LÖWY, 2015, p. 18).

Marx e Engels, em A Ideologia Alemã, dão à ideologia um sentido bastante pejorativo, sendo ela "um conceito crítico que implica ilusão, ou se refere à consciência deformada da realidade 
que se dá através da ideologia dominante: as ideias das classes dominantes são as ideologias dominantes na sociedade" (LÖWY, p. 19).

O criminólogo italiano, Alessandro Baratta, explicitamente calcado em premissas marxista, ao tratar do senso comum sobre o crime, organiza o pensamento tradicional quanto ao crime e seu controle, sob o nome de Ideologia da Defesa Social, desde logo advertindo os leitores de sua obra “Criminologia Crítica e Crítica do Direito Penal”, que usa o termo ideologia em sentido pejorativo, o mesmo exposto por Marx e Engels em sua "Ideologia Alemã".

Ideologia seria também superestrutura, um compêndio de ilusões, uma vez que as ideias não possuem existência própria mas derivam de um determinado substrato material. Para Cirino dos Santos, a ideologia oficial faz crer em uma ordem social imaginária. "Para Marx, a ideologia é uma forma de falsa consciência, correspondendo a interesse de classe” (LÖWY, 1987, p. 10).

Tal é a concepção também expressa por Marilena Chauí (2011, p. 15):

\begin{abstract}
A ideologia, forma específica do imaginário social moderno, é a maneira necessária pela qual os agentes sociais representam para si mesmo o aparecer social, econômico e político, de tal sorte que essa aparência (que não devemos simplesmente tomar como sinônimo de ilusão ou falsidade), por ser o modo imediato e abstrato de manifestação do processo histórico, é o ocultamento ou a dissimulação do real. Fundamentalmente, a ideologia é um corpo sistemático de representações e de normas que nos 'ensinam' a conhecer e a agir.
\end{abstract}

A chamada Ideologia da Defesa Social em linhas gerais afirma que o Estado tem legitimidade para combater o crime, sendo a vontade social diante dele; que na sociedade há bons e maus, caracterizando a criminalidade apenas a minoria da população, identificável e também passível de eliminação; o crime seria escolha livre do cidadão que, sendo igual a os demais, opta por romper o pacto social; o Direito Penal é um só e aplicado de forma idêntica contra todos que o transgridam; a lei é expressão da vontade geral e apenas reconhece, não cria, o caráter criminoso de determinadas condutas; as penas aplicadas pelo Estado têm finalidade ética de exercer prevenção geral e especial.

Desta descrição, conclui-se que tal ideologia é pautada na ilusão de um consenso social sobre quem sãos os bons e maus, quais são as condutas criminosas e estar o Estado legitimado a tomar as medidas necessárias contra o crime, na tentativa de o prevenir e extinguir. Ainda conforme CHAUÍ (2001, p. 16-17), a ideologia é um discurso sempre fora do tempo e fora do lugar, inquinado de lacunas deliberadas, que operam para assegurar o ocultamento das informações mais importantes.

A questão levantada no presente trabalho é: quem orquestra o suposto consenso? E a resposta que encontramos com Faoro é: o estamento.

Tal pensamento, pregado por aqueles que conduzem o Estado e apregoado por veículos de 
comunicação social, dá aos aplicadores do direito a sensação de militar do lado justo, de "fazer justiça”, quando estão aprofundando desigualdades.

Observa-se que dentro da sociedade não é dado a todos ser atores dos processos sociais e formadores dos saberes sobre os mais diversos temas que interessam à vida social. $\mathrm{O}$ cientificismo e tecnicismo modernos trouxeram a noção de que há indivíduos e grupos de saber privilegiado, cujos discursos determinam o que se deve pensar e como se deve agir. São os detentores do que Marilena Chauí (2011, p. 19) chama de "discurso competente":

O discurso competente é aquele que pode ser proferido, ouvidor e aceito como verdadeiro ou autorizado (estes termos agora se equivalem) porque perdeu os laços com o lugar e o tempo de sua origem. [...] O discurso competente é o discurso instituído. É aquele no qual a linguagem sofre uma restrição que poderia ser assim resumida: não é qualquer um que pode dizer a qualquer outro qualquer coisa em qualquer lugar e em qualquer circunstância.

Uma vez que a dominação pela força não perdura, deve se dar também pelas ideias, que se tornam de todos os membros da sociedade, mesmo dos não beneficiados por elas (por exemplo, mesmo os que não têm propriedade a defendem).

Tem-se então que "a classe que é o poder material dominante numa determinada sociedade é também o poder espiritual dominante" (MARX; ENGELS, 1989, p. 47).

A este tal poder espiritual poderíamos dar também o nome de ciência.

Portanto, da base material real (econômica), onde há a dominação dos proletários pelos proprietários, surgem as superestruturas, entre elas científica e a jurídica, sendo o direito diretamente determinado pelas relações de produção em determinada época. Conforme Marx e Engels (1989, p. 71), o direito não tem uma história própria mas está ligado à história da propriedade privada. A própria consciência de uma época é determinada por suas condições materiais. ${ }^{4}$

Observa-se aqui a influência do anterior patrimonialismo e sua continuidade na manipulação do processo legislativo pelo estamento.

Também Luiz Werneck Vianna (1999, p. 35) explica a sociedade estamental:

Não seríamos propriamente um caso ocidental, uma vez que, aqui, o Estado, por anteceder aos grupos de interesses, mais do que autônomo em face da sociedade civil, estaria empenhado na realização de objetivos próprios aos seus dirigentes, enquanto a administração pública, vista como um bem em si mesmo, é convertida em um patrimônio a ser explorado por eles. Inscritos no Oriente político, conheceríamos um sistema político de cooptação sobreposto ao de representação, uma sociedade estamental igualmente sobreposta à estrutura de classes, o primado do direito administrativo sobre o direito civil,

\footnotetext{
4 'Em uma sociedade desigual, o crime é contra a propriedade (e mesmo as várias 'infrações contra a pessoa' são, frequentemente, cometidas na busca da propriedade". (TAYLOR; WALTON; YOUNG, 1980, p. 40).
} 
a forma de domínio patrimonial-burocrática e o indivíduo como um ser desprovido de iniciativa e sem direitos diante do Estado.

Tal sociedade estamental torna a ideologia impessoal, para tanto, seu principal instrumento é a lei, o Direito. É portanto que, para conhecer o direito, deve-se estudar a sociedade, também ela superestrutura. "A ideologia burguesa é institucionalizada nas formas jurídicas e políticas do Estado - que reproduzem as relações sociais" (SANTOS, 2006, p. 52).

A estrutura da sociedade é a base econômica, por sua vez determinante da superestrutura. A partir dela, em que se dá o relacionamento entre relações de produção e forças produtivas, erguese a superestrutura e os modos da classe economicamente relevante se impõem como conjunto de representações da classe dominante. Assim, através da dominação a partir da ideologia, vê-se o mundo com os valores da classe dominante, do estamento. Este conjunto se espraia à sociedade que verá o mundo de forma invertida.

A Criminologia Crítica, inspirada no pensamento marxista, pretende deslegitimar o discurso ideológico relacionado ao Direito e Sistema Penais, verificando que esta não passa de um discurso sem relação com a prática diária do mesmo, reconhecendo o antagonismo inerente à sociedade, assumindo a sociologia do conflito e afirmando, por exemplo, que não é possível sustentar que a lei é expressão da vontade geral, uma vez que as interferências das classes dominantes no processo legislativo são patentes; que o crime não é fruto de mau uso do livre arbítrio, mas determinado pelo contexto econômico; que a estigmatização oriunda da reação estatal ao crime impede o efeito preventivo esperado das penas; que o rótulo de criminoso, tal como propriedade e igualdade, não são distribuídos de forma igual dentro da sociedade, apontando-se fatores econômicos, jurídico-formais e sociais que determinam as escolhas de condutas e pessoas a serem criminalizadas. "As teorias do conflito pressupõem a existência na sociedade de uma pluralidade de grupos e subgrupos que, eventualmente, apresentam discrepâncias em suas pautas valorativas" (PABLOS DE MOLINA; GOMES, 2000, p. 287).

Cite-se Sérgio Salomão Shecaira (2004, p. 331):

\footnotetext{
A premissa do pensamento estava inescondivelmente ancorada no pensamento marxista, pois sustentava ser o delito um fenômeno dependente do modo de produção capitalista. Segundo afirmação de Marx, com sua proverbial ironia, o crime produziria professores e livros, todo o sistema de controle social - juízes, policiais, promotores, jurados -, métodos de tortura; teria feito evoluir procedimentos técnicos, datiloscópicos, químicos e físicos, para detectar falsificações; favoreceria, assim, fabricantes e artesãos, rompendo a monotonia da vida burguesa: enfim, daria, desta maneira, um estímulo às forças produtivas. Vale dizer, o centro das atenções do marxismo em relação à criminalidade é o seu caráter de crítica ao funcionalismo do pensamento criminal. A lei penal nada mais é do que uma estrutura (também designada superestrutura) dependente do sistema de produção
} 
(infra-estrutura ou base econômica). (GRIFO NOSSO )

E Pablos de Molina (p. 288), reitera a concepção conflitual da sociedade e o crime como reação à exploração já denunciada pelo marxismo:

O Direito representa os valores e interesses das classes ou setores sociais dominantes, não os gerais da sociedade, aplicando a justiça penal as leis de acordo com os referidos interesses; o comportamento delitivo é uma reação à desigual e injusta distribuição de poder e riqueza na sociedade.

Certamente, definir alguém como criminoso é ótima forma de o controlar, de neutralizar as vítimas da exploração e da opressão social. O crime permite ao Estado seu monopólio no exercício da violência legítima, demonstração de seu poder no controle as massas. "À medida que as sociedades capitalistas se industrializam, a divisão entre as classes sociais vai crescendo e as leis penais vão, progressivamente, tendo que ser aprovadas e aplicadas para manter uma estabilidade temporária, encobrindo confrontações violentas entre as classes sociais" (SHECAIRA, 2004, p. $334)$.

A criminalização é instrumento eficiente para controlar tanto os trabalhadores inseridos no mercado de trabalho, para que aceitem as condições de exploração a que são submetidos, quanto, e principalmente, aqueles que não conseguem vender sua força de trabalho, para que também não se insurjam e subvertam a divisão de poder.

É proposto assim um debate quanto à própria definição do que é crime, afastando-se o dogma da neutralidade do Direito e da Justiça. Alguns pensadores, ao lado da pobreza, entendem como fatores criminógenos também o individualismo, consumismo e competição a todos impostos em nossos dias, bem como discriminações raciais e sexuais. Verificam que o crime não é apenas interclassista, mas também intraclassista, sendo os menos favorecidos os que mais sofrem com a criminalidade.

Pugna-se pela redução da atuação penal do Estado e ao mesmo tempo sua extensão para outras áreas de maior interesse da população (crimes violentos, contra crianças, relacionados às relações de trabalho, de consumo e ao patrimônio público ou por motivos raciais), de forma a não jogar trabalhadores contra trabalhadores, isto seria pensar uma "criminalidade para os oprimidos".

Ainda, há as ideias abolicionistas, reiterando a afirmação de que o sistema penal serve apenas para reprodução de desigualdades. Uma das matrizes do pensamento abolicionista é marxista. Compreendendo o sistema penal como meio de esconder os conflitos sociais, de acordo com Shecaira (2004, p. 347): 
Partem da visão consagrada na 'ideologia alemã' quanto ao conceito de alienação, que conduz classes antitéticas a terem um pensamento conducente a uma ideia de colaboração entre elas. A mudança dessa concepção, que desaguaria no socialismo, produziria não só mais justiça social, mas especialmente mais liberdade, pois as decisões sociais seriam tomadas coletivamente, o que permitiria uma própria redução do controle social sobre a maioria.

O sistema penal deveria ser abolido por já vivermos sem ele, uma vez que a cifra de crimes jamais objeto da atuação estatal é altíssima e pelo caráter seletivo, estigmatizante e burocrata do sistema, fundado em uma falsa concepção consensual da sociedade, que ignora a vítima, apenas produz a dor do réu sem qualquer efeito de reabilitação do mesmo, servindo apenas à função simbólica de afirmação do poder estatal e proteção da propriedade privada.

\section{LEI COMO EXPRESSÃO DA VONTADE GERAL?}

$$
\begin{array}{r}
\text { De quem é? } \\
\text { De quem é? } \\
\text { Às vezes você me domina } \\
\text { Pensando que eu sou teu dono } \\
\text { Às vezes você me dá nojo } \\
\text { Seguindo feliz o rebanho } \\
\text { Onde vai dar tudo isso? } \\
\text { (Cazuza) }
\end{array}
$$

Diante de todo o exposto, é possível chegar ao item final do presente texto, que é o encontro entre a ideia de sociedade estamental e um dos princípios da Ideologia da Defesa Social, qual seja, o princípio do Interesse Social e Delito Natural.

Afirma o princípio que os interesses defendidos pelo Direito Penal são comuns à toda a sociedade, sendo que apenas uma parte dos crimes viriam de arranjos políticos e econômicos, os chamados DELITOS ARTIFICIAIS. Assim explica Alessandro Baratta (2002, p. 117): “o núcleo central dos delitos contidos nos códigos penais das nações civilizadas representa ofensa de interesses fundamentais, de condições essenciais à existência de toda sociedade. Os interesses protegidos pelo direito penal são interesses comuns a todos os cidadãos".

Esta seria uma chamada concepção naturalista da criminalidade, oriunda da criminologia tradicional, que retira os tipos ${ }^{5}$ da história, como sendo violação a interesses e necessidades próprios de toda a comunidade.

A crítica vem apontar o que já se pontuou durante todo o presente texto: a ideologia da

\footnotetext{
${ }^{5}$ Descrições formais dos crimes, constantes dos códigos e leis que definem que condutas são consideradas criminosas.
} 
defesa social pressupõe a homogeneidade dos valores e interesses ofendidos pelo crime, calcada no dogma de que, mediante uma democracia representativa, a lei se tornaria a expressão da vontade geral.

Porém, as teorias criminológicas da Reação Social ou Etiquetamento (Labeling Approach), que não são o objeto principal do presente trabalho, mostram que o desvio é algo construído pelas definições legais e reações sociais às condutas. A criminalidade não é qualidade ontológica da conduta, mas status social atribuído através de processos de definição e mecanismos de reação (BARATTA, 2002, p. 118).

Pergunta-se: com base em que leis sociais se distribui e se concentra o poder de definição? Entra aí então a análise já feita sobre as diferenças de poder e de interesses entre grupos sociais, bem como do grau de influência que os mencionados grupos detém na definição das normas sociais e jurídicas.

Não é possível ver os processos de interação, que atribuem os rótulos à pessoas, classes e condutas, como se acontecessem no mesmo plano, como se todos os indivíduos e grupos se encontrassem no mesmo patamar de poder. Numa perspectiva macrossociológica, vê-se o conflito entre grupos como a explicação para a criminalização.

Observa-se então que os interesses que formam e aplicam o Direito Penal são dos grupos que influem nos processos de criminalização, não são interesses comuns, sendo que a criminalidade é criada pelo processo de criminalização. "A criminalidade e todo o Direito Penal têm, sempre, natureza política" (BARATTA, 2002, p. 119) e os delitos artificiais (fruto de arranjos políticos e econômicos) na verdade não são poucos. Percebe-se assim a instabilidade, desequilíbrio, heterogeneidade dos interesses e do consenso dentro da sociedade.

Rompe-se de tal forma o mito de uma sociedade estática. Segundo Dahrendorf a sociologia que se baseia em modelos de equilíbrio, é utópica. É necessário ver a mudança e o conflito como normas universais. A sociedade e a organização não se mantém pelo consenso, mas pela coação, pelo domínio que uns exercem sobre os outros. Afirma Baratta (2002, p. 123, GRIFO NOSSO): “o objeto do conflito, na sociedade tardo-capitalista, não são as relações materiais de propriedade, de produção e de distribuição, mas sim a relação política do domínio de alguns indivíduos sobre outros".

O conflito é resultado da relação política de domínio. Inclui-se então a luta pelo poder como objeto do conflito, mas também bens materiais e imateriais, com uma distinção entre conflito realísticos (fim em si mesmo) e não realísticos. O desvio inovador seria um conflito realístico, procurando alcançar os meios indicados pela cultura, enquanto outros serviriam apenas para 
descarregar tensões.

O criminoso faz parte da minoria sem base pública suficiente para dominar e controlar o poder de polícia. O criminoso não é um dos “donos do poder”. É o que afirma Salah Khaled Junior (2015, GRIFO NOSSO):

\begin{abstract}
Sem dúvida, a realidade concreta vivida pelos brasileiros está ainda muito distante do projeto delineado pela Constituição Cidadã. Não há exagero algum aqui: em pleno Estado Democrático de Direito, ainda enfrentamos enormes dificuldades para superar os inúmeros obstáculos à concretização da Constituição, particularmente no que diz respeito a quem está fora dos círculos privilegiados nos quais são tomadas as decisões sobre o que vale e não vale e sobre o que pega e não pega.
\end{abstract}

Baratta vai ainda além da visão dos teóricos do conflito, levando tal raciocínio não apenas ao que chama de criminalização primária (lei penal), mas também à criminalização secundária (aplicação da lei).

Tem-se portanto que a criminalidade é um status social atribuído a uma pessoa por quem tem poder de definição. Os dois grupos em constante conflito seriam os sujeitos do poder e os sujeitos ao poder. Vai se verificando que a noção de crime depende portanto da noção de Estado. Turk afirma: "não pode existir crime, se não existe Estado" (citado por BARATTA, 2002, p. 133). Assim, o estudo da criminalidade é o estudo das relações de status e poder. Lembra-se aqui novamente Faoro: “onde a mobilização de ideais manipulados não consegue manter o domínio, a repressão toma o seu lugar, alternando o incentivo à compressão" (2008, p. 880).

Turk já não se atém apenas à criminalização primária (lei/definição legal), mas aborda também a atuação dos órgãos oficiais de repressão, que tendem também a concentrar sua atuação entre grupos desfavorecidos. Percebe que há uma reação institucional diante da criminalidade e outra não institucional.

Baratta mantém a crítica à incompletude de tais teorias, que não iriam um passo além da pura descrição dos fenômenos, com sociologia pouco provida do ponto de vista da economia política. Mas reconhece que contribuíram ao transformar a perspectivas microssociológicas em macrossociológicas, tendo sido uma fase mais avançada da criminologia liberal contemporânea, observando o crime não apenas como antagonismo entre sociedade e indivíduo, mas entre grupos sociais.

Salah Khaled Junior (2015) nos aponta dois exemplos recentes que demonstram como os movimentos do poder legislativo servem a interesses bastante específicos:

Os primeiros meses de 2015 ficarão marcados na história do país pela investida selvagem 
contra os direitos fundamentais da população vulnerável. Terceirização e redução da maioridade penal fazem parte de um movimento conjunto, cujo sentido é dado por um pensamento proposto como único, mas que claramente remete ao receituário neoliberal a que serve. Trata-se de uma investida perversa, que visa deliberadamente reconduzir o país ao seu passado autoritário e promover a verticalização das relações sociais: de um lado, a legislação trabalhista é apontada como entrave ao desenvolvimento do país, como se fosse um arcaísmo a ser superado; de outro lado, a redução da maioridade penal é vendida como medida capacitada para a realização de milagres que jamais teria como proporcionar. Em outras palavras, estamos diante de uma iniciativa orientada pelo que há de mais perverso em termos de política social e econômica: estado social mínimo e estado penal máximo é o projeto capitaneado por essa intenção de subjugação do outro. A estratégia consiste em ampliar o espectro de criminalização da pobreza e vulnerar o trabalhador diante da extração de forças típica da face mais perversa da dinâmica capitalista. Viva a competição! Está dada a largada!

Principalmente no que se refere à flexibilização de direitos trabalhistas (que não são o objeto principal do presente trabalho), se observa como a lei não serve aos interesses sociais e sim a arranjos econômicos e políticos bastante específicos. É necessário atender ao mercado.

\title{
5 CONCLUSÕES
}

\author{
De quem é? \\ De quem é? \\ Prender alguém ou ser preso \\ Quem é o mais infeliz? \\ $E u$, dando ordem o dia inteiro? \\ E você, que nem sabe o que diz?
}

(Cazuza)

A partir das reflexões expostas no presente trabalho procurou-se demonstrar que o dogma da lei como expressão da verdade geral é na realidade uma forma de ingenuidade social, como uma maneira de explicar a si mesma as razões de sua submissão às regras, mesmo quando estas vêm em seu prejuízo.

Evidencia-se que a lei na realidade não expressa necessariamente os interesses sociais e sim interesses daqueles que detém os mecanismos de poder. Talvez esta não seja a maior conclusão aqui presente, não sendo grande novidade aos que estudam o poder e o Estado. A contribuição que se procurou trazer foi relacionar tal fenômeno à sociedade estamental exposta por Raymundo Faoro e a chamada Ideologia da Defesa Social, abordada por Alessandro Baratta. Ou seja, buscou-se demonstrou-se que a seleção das condutas criminosas e dos indivíduos considerados criminosos não é aleatória assim como não é fruto apenas do conflito de classes. Tais escolhas dependem dos interesses dos verdadeiros donos do poder, ou seja, os herdeiros do patrimonialismo que se organizam enquanto estamento.

Daí a importância de se debater o tema e questionar o mencionado dogma, assim como 
pensar sobre a construção do saber em nossa sociedade, que muitas vezes serve para legitimar a manutenção do poder da forma como já exposta, determinando quem são os capacitados ao discurso competente e à definição ideológica de uma sociedade.

Conclui-se com as palavras de Marilena Chauí, também ao encerrar a apresentação da primeira edição da obra Cultura e Democracia (2011, p. 14):

\begin{abstract}
Acredito que, se procurarmos desvendar os mecanismos de produção da incompetência social, teremos alguma possibilidade de desfazer internamente o discurso da competência. Não se trata, evidentemente, de confundir a impenetrabilidade imediata, que é real, com um saber transparente, de imediato comunicável a todos, pois essa imagem da plena comunicação e da absoluta transparência dos produtos da cultura é o que permite sua banalização pelos meios de comunicação de massa.
\end{abstract}

\title{
REFERÊNCIAS
}

BARATTA, Alessandro. Criminologia crítica e crítica do direito penal: introdução à sociologia do direito penal. 3. ed. Rio de Janeiro: Revan, 2002.

BONAVIDES, Paulo. Ciência política. 10 ed. São Paulo: Malheiros, 2004.

CAZUZA; ISRAEL, George; ROMERO, Nilo. De quem é o poder? In: Kid, Warner Music, 1989.

CHAUÍ, Marilena. Cultura e Democracia - O Discurso Competente e Outras Falas. São Paulo: Cortez, 2011.

FAORO, Raymundo. Os donos do poder: formação do patronato político brasileiro. 4. ed. São Paulo: Globo, 2008.

FERNANDES, Florestan(org). Marx Engels. São Paulo: Ática, 1989.

GOMES, Luiz Flávio e GARCÍA-PABLOS DE MOLINA, Antonio. Criminologia. 3 ed. São Paulo: Revista dos Tribunais, 2000.

KHALED JUNIOR, Salah. O "pensamento único" e o novo "jeitinho" legislativo: a investida dos "donos do poder" contra a população vulnerável. Disponível em: < http://emporiododireito.com.br/o-pensamento-unico-e-o-novo-jeitinho-legislativo-a-investida-dosdonos-do-poder-contra-a-populacao-vulneravel-por-salah-khaled-jr/>. Acesso em: 13 out 2015.

LOWY, Michael. As aventuras de Karl Marx contra o Barão de Münchhausen - Marxismo e positivismo na sociologia do conhecimento. São Paulo: Busca vida, 1987.

Ideologias e ciência social. 20 ed. São Paulo: Cortez, 2015. 
MARX, Karl; ENGELS, Friederich. Manifesto do partido comunista. Trad. Pietro Nassetti. São Paulo: Martin Claret, 2003.

A ideologia alemã. São Paulo: Martins Fontes, 1989.

SANTOS, Juarez Cirino dos. Criminologia radical. 2 ed. Curitiba: ICPC-Lumen júris, 2006.

SHECAIRA, Sérgio Salomão. Criminologia. São Paulo: Revista dos Tribunais, 2004.

TAYLOR, Ian.; WALTON, Paul; YOUNG, Jock. Criminologia crítica. Rio de Janeiro: Graal, 1980 .

TOSCANO JUNIOR, Rosivaldo. Brasil: Faoro explica... Nietzsche e Sartre apontam.

Disponível em: < http://emporiododireito.com.br/brasil-faoro-explica-nietzsche-e-sartre-apontampor-rosivaldo-toscano-jr/>. Acesso em: 13 out 2015.

VIANNA, Luiz Werneck. Weber e a interpretação do Brasil. Disponível em:

<http://novosestudos.org.br/v1/files/uploads/contents/87/20080627_weber_e_a_interpretacao.pdf.

$>$ Acesso em: 28 jul 2015. 